\title{
Efeito dos níveis de suplementação no desempenho de bovinos em sistema de semi-confinamento
}

\author{
Felipe Cecconello BENTO ${ }^{1}$, Edgar Antonio ROVANI ${ }^{2}$, Gabriel Ferreira MESQUITA ${ }^{3}$, \\ Lucas Roberto Batista RUIZ ${ }^{3}$, Maria Isabel Leite da SILVA ${ }^{1}$, Paulo Sergio de Andrade MOREIRA², \\ Angelo POLIZEL NETO ${ }^{3}$, Helen Fernanda Barros GOMES ${ }^{3}$
}

\author{
${ }^{1}$ Universidade Federal de Mato Grosso, Cuiabá, MT, Brasil. \\ ${ }^{2}$ Universidade Federal de Mato Grosso, Sinop, MT, Brasil. \\ ${ }^{3}$ Universidade Federal de Mato Grosso, Rondonopólis, MT, Brasil. \\ E-mail: felipe.cecconello.bento@gmail.com
}

Recebido em agosto/2018; Aceito em julho/2019.

\begin{abstract}
RESUMO: Objetivou-se avaliar o efeito dos níveis de suplementação sobre o desempenho de bovinos em sistema de terminação no período das águas em pastagem de capim Panicum maximum cv. Mombaça e sua viabilidade econômica. No experimento foram utilizados 68 bovinos não castrados da raça Nelore, sendo conduzido segundo delineamento inteiramente casualizado, com dois níveis de suplementação de concentrado na proporção de $1,2 \%$ e 1,8\% peso vivo (PV) com base na matéria seca (MS). Os níveis de suplementação não diferiram nos pesos corporais dos animais nas pesagens feitas durante o experimento e final. Os animais suplementados com $1,8 \%$ do PV obtiveram maior ganho de peso total, área de olho de lombo final e espessura de gordura subcutâneo final. Os níveis de suplemento não influenciaram significativamente no peso de carcaça quente, conformação da carcaça e rendimento da carcaça. Os animais que receberam o maior nível de suplementação tiveram maior acabamento da carcaça. O maior nível de suplementação gerou maior custo inicial, médio, final e maior custo por ganho de peso dos animais. Assim, a suplementação com 1,2\% do PV resulta em menor custo por quilo de carne produzida, sendo o mais indicado para bovinos terminados a pasto.
\end{abstract}

Palavras-chave: análise econômica, confinamento a pasto, Panicum maximum cv. Mombaça, pastejo, terminação.

\section{Effect of supplementation levels on beef cattle performance in semi-confined systems}

\begin{abstract}
The objective of this study was to evaluate the effect of the supplementation levels on the performance of cattle in the finishing system in the period of waters in pasture of Panicum maximum cv. Mombasa and its economic viability. In the experiment, 68 Nellore bulls were used, and were conducted in a completely randomized design with two levels of concentrate supplementation at the ratio of $1.2 \%$ and $1.8 \%$ live weight (LW) based on the dry matter (DM). Supplementation levels did not differ in body weights of animals during weighing done during the experiment and final. The animals supplemented with $1.8 \%$ of the LW obtained greater total weight gain, final loin eye area and final subcutaneous fat thickness. Supplement levels did not significantly influence hot carcass weight, carcass conformation, and carcass yield. The animals that received the highest level of supplementation had a better finishing of the carcass. The higher level of supplementation generated higher initial, average, final cost and higher cost for weight gain of the animals. Thus, the supplementation with $1.2 \%$ of the $\mathrm{LW}$ results in a lower cost per kilogram of meat produced, being the most suitable for beef cattle.
\end{abstract}

Keywords: economic analysis, feedlot in pasture, Panicum maximum cv. Mombaça, grazing, termination.

\section{INTRODUÇ̃̃O}

A pecuária brasileira se desenvolveu principalmente pela criação de bovinos a pasto, sendo esse sistema o de forma mais simples e com o menor custo com a alimentação, em detrimento das gramíneas tropicais serem a principal fonte de nutrientes, capazes de oferecer energia a partir de fibra em detergente neutro (FDN) (SOUZA et al., 2010).

O sistema de criação de bovinos nos trópicos tenta explorar fortemente a estação das chuvas, da qual é o período de maior potencial forrageiro, que ocorre durante os períodos que nessas regiões culminam com a concentração de altas temperaturas e luminosidade, o que torna mais favorável o aumento do potencial de desenvolvimento forrageiro.
Contudo, o elevado desenvolvimento dessas gramíneas no período das chuvas faz com que haja maturação das plantas, resultando em elevados teores de compostos da parede celular, tornando o pasto com maior qualidade disponível por um pequeno período (LAZZARINI et al., 2009), porém podem ser evitados com a adoção de manejo adequado da pastagem. As forrageiras tropicais variam de qualidade durante o período de pastejo e, consequentemente, apresentam restrições nutricionais que reduzem a ingestão e a digestibilidade do pasto (DETMANN et al., 2014).

O uso do suplemento aumenta a digestibilidade da matéria seca e a eficiência de síntese microbiana. Apesar das forrageiras nessa época do ano não terem baixos índices 
proteicos, a alta proporção dos compostos nitrogenados totais do pasto podem ser encontrados na forma insolúvel em detergente neutro, que compreende a fração de lenta e incompleta degradação, sendo capaz de reduzir a quantidade de compostos nitrogenados a microbiota ruminal (COSTA et al., 2011).

Desta forma, atrelado a maior busca pela eficiência produtiva, é importante que o sistema de produção adotado proporcione maior produtividade de forma economicamente viável. Com isso, a utilização de suplementação nos períodos de chuva, quando há maior oferta de forragem, proporciona maior fornecimento de nutrientes limitantes e aumenta a eficiência de utilização do pasto que, consequentemente, aumenta a taxa de lotação e desempenho dos bovinos, bem como, reduz os ciclos de produção, proporcionando condições de abate mais precocemente (REIS et al., 2009).

Nesse sentido, este estudo foi desenvolvido com o objetivo de avaliar economicamente o efeito dos níveis de suplementação sobre o desempenho de bovinos terminados em semi-confinamento no período das águas em pastagem de capim Panicum maximum cv. Mombaça.

\section{MATERIAL E MÉTODOS}

$\mathrm{O}$ experimento foi realizado na área experimental da $\mathrm{O}$ experimento foi realizado na fazenda Água Boa I, localizada no município de Marcelândia, no estado do Mato Grosso, no período de novembro de 2014 a março de 2015.

Foram utilizados 68 bovinos não castrados da raça Nelore, com peso corporal médio inicial de $388 \pm 73 \mathrm{~kg}$. O experimento compreendeu o período de engorda dos bovinos que ficaram em pastagem de Mombaça (Panicum maximum cv. Mombaça), em regime de semi-confinamento, por um período de 129 dias.

O experimento foi estruturado e conduzido segundo delineamento inteiramente casualizado, com dois níveis de suplementação de concentrado na proporção de 1,2\% e 1,8\% peso vivo (PV) com base na matéria seca (MS) com 34 repetições cada tratamento.

Os animais receberam suplemento proteico-energético balanceado de acordo com as tabelas Brasileiras de Exigências
Nutricionais (VALADARES FILHO et al., 2006) (Tabela 1), para o ganho médio de peso de $1,2 \mathrm{~kg} /$ dia. A ração foi composta por milho, farelo de soja, caroço de algodão, suplemento mineral com leveduras, ureia e calcário, contendo $18 \%$ de proteína bruta $(\mathrm{PB})$ e $73 \%$ de nutrientes digestíveis totais (NDT).

A área experimental era composta de 24 alqueires, divididos em quatro piquetes de seis alqueires cada, providos de comedouro com cobertura, respeitando uma distância de 0,5 $\mathrm{m}$ por animal, bebedouro. Os bovinos foram manejados em sistema de pastejo alternado, os animais alternavam os piquetes a cada período (28 dias)

Os animais foram identificados com brinco numerado na orelha, pesados e distribuídos aleatoriamente em dois grupos nos piquetes para garantir as médias de peso corporal semelhantes entre os grupos. Todos os animais foram submetidos a controle de ecto e endoparasitas e a vacinações, conforme calendário sanitário local.

A dieta foi fornecida em dois horários durante o dia, às $6 \mathrm{~h}$ e às $17 \mathrm{~h}$. Os animais foram submetidos a 14 dias de adaptação à alimentação e aos piquetes. O pasto foi avaliado no início do experimento, por meio da técnica de pastejo simulado, para verificar a quantidade e qualidade da matéria disponível. A mesma avaliação foi realizada a cada 28 dias de pastejo, durante todo o experimento, resultando em quatro períodos de avaliação. As amostragens do pasto para composição física e química foram feitos através do pastejo simulado (Tabela 2).

O pastejo simulado foi realizado conforme Johnson (1978), depois de um período de observação cuidadosa, no qual foram observados, além do comportamento de pastejo dos animais, área, altura e partes da planta que estavam sendo consumidas. As amostras foram colhidas pelo mesmo observador, manualmente, na tentativa de se obter uma porção da planta similar àquela colhida pelos animais.

Essas amostras foram pesadas e separadas em folha, colmo e material morto sendo pesadas e secas em estufa, para avaliação da disponibilidade de folha, colmo e material morto por piquete a cada 28 dias.

Tabela 1. Dieta fornecida para os animais do experimento.

Table 1. Diet provided to experiment animals.

\begin{tabular}{lcccccc}
\hline \multirow{2}{*}{ Item $^{2}$} & \multicolumn{5}{c}{ Dieta $^{1}$} \\
\cline { 2 - 6 } & Milho & Farelo Soja & Caroço Algodão & Suplemento mineral com Leveduras & Ureia & Calcário \\
\hline Proteína Bruta & 9,00 & 45,00 & 27,00 & 56,25 & 281,00 & - \\
Nutrientes Digestíveis Totais & 80,00 & 78,00 & 65,00 & - & - & - \\
Fibra Bruta & 2,30 & 6,00 & 14,00 & - & - & - \\
Extrato Etéreo & 2,90 & 1,50 & 1,50 & - & - & - \\
Cálcio & - & - & 0,28 & 8,10 & - & 38,00 \\
Fósforo & - & - & 0,95 & 1,76 & - \\
Sódio & - & - & 0,04 & 6,00 & - \\
\hline
\end{tabular}

${ }^{1}$ Percentual dos ingredientes da dieta; ${ }^{2}$ Percentual da matéria seca.

Tabela 2. Composição física da pastagem avaliada durante o período experimental.

Table 2. Physical composition of the pasture evaluated during the experimental period.

\begin{tabular}{lccccc}
\multicolumn{1}{c}{ Item } & \multicolumn{2}{c}{ Período de coleta } & \multirow{2}{*}{ CV } \\
\cline { 2 - 5 } & 1 & 2 & 3 & 4 & 76,82 \\
\hline Altura do pasto $(\mathrm{cm})$ & 46,00 & 85,50 & 93,90 & 81,90 & 14,78 \\
Peso da coleta $(\mathrm{kg})$ & 2,54 & 2,19 & 3,02 & 3,07 & 2,71 \\
Peso das folhas $(\mathrm{kg})$ & 1,14 & 0,98 & 1,34 & 1,41 & 1,22 \\
Peso dos colmos (kg) & 1,06 & 0,92 & 1,26 & 1,26 & 24,99 \\
Peso do material morto $(\mathrm{kg})$ & 0,32 & 0,28 & 0,39 & 0,39 & 2,13 \\
\hline
\end{tabular}

${ }^{1} 1$ - 28 dias, 2 - 56 dias, 3 - 84 dias e 4 - 112 dias; CV: Coeficiente de variação. 
No laboratório as amostras foram submetidas às análises de matéria seca (MS), proteína bruta (PB), extrato etéreo (EE), conforme técnicas descritas por AOAC (2007), fibra insolúvel em detergente neutro (FDN) e ácido (FDA) segundo Van Soest et al. (1991) (Tabela 3).

Para a condução das pesagens, foi utilizada uma instalação próxima à área de pastagem, que se constituía de um curral de contenção e uma balança tipo brete, com capacidade para $2.000 \mathrm{~kg}$. As pesagens foram realizadas no início e ao final do período experimental, em jejum de sólidos, com objetivo de reduzir possíveis diferenças quanto ao enchimento do trato digestivo e foram feitas também pesagens intermediárias sem jejum, a cada 28 dias, para ajuste do fornecimento do suplemento.

Tabela 3. Composição química (\% de matéria seca) do pasto avaliada durante o período experimental.

Table 3. Chemical composition (\% dry matter) of the pasture evaluated during the experimental period.

\begin{tabular}{|c|c|c|c|c|c|}
\hline \multirow{2}{*}{ Item } & \multicolumn{4}{|c|}{ Período de coleta } & \multirow{2}{*}{ Média } \\
\hline & 1 & 2 & 3 & 4 & \\
\hline Matéria seca & 21,67 & 33,21 & 35,35 & 35,21 & 31,36 \\
\hline Matéria mineral & 0,63 & 0,54 & 1,03 & 0,64 & 0,71 \\
\hline Extrato etéreo & 3,77 & 3,65 & 2,24 & 1,70 & 2,84 \\
\hline Proteina bruta & 12,63 & 7,25 & 6,88 & 7,62 & 8,59 \\
\hline Fibra insolúvel em detergente neutro & 69,99 & 59,99 & 60,73 & 55,79 & 61,62 \\
\hline Fibra insolúvel em detergente ácido & 36,67 & 30,37 & 30,35 & 26,57 & 30,99 \\
\hline Matéria seca & 14,76 & 26,75 & 29,69 & 32,38 & 25,89 \\
\hline Matéria mineral & 0,77 & 0,63 & 0,71 & 0,64 & 0,69 \\
\hline Extrato etéreo & 2,56 & 1,54 & 1,48 & 1,46 & 1,76 \\
\hline Proteina bruta & 9,81 & 4,85 & 4,28 & 3,6 & 5,63 \\
\hline Fibra insolúvel em detergente neutro & 73,63 & 72,82 & 70,61 & 71,47 & 72,13 \\
\hline Fibra insolúvel em detergente ácido & 39,69 & 44,64 & 41,13 & 46,04 & 42,87 \\
\hline Matéria seca & 23,98 & 74,97 & 67,37 & 69,28 & 58,90 \\
\hline Matéria mineral & 0,91 & 0,87 & 2,08 & 1,34 & 1,30 \\
\hline Extrato etéreo & 0,94 & 0,56 & 0,35 & 0,60 & 0,61 \\
\hline Proteina bruta & 4,41 & 4,44 & 4,71 & 4,61 & 4,79 \\
\hline Fibra insolúvel em detergente neutro & 78,38 & 64,92 & 64,74 & 68,04 & 69,02 \\
\hline Fibra insolúvel em detergente ácido & 41,93 & 40,87 & 39,38 & 49,91 & 43,02 \\
\hline
\end{tabular}

Juntamente com as pesagens realizou-se avaliação da espessura de gordura subcutâneo (EGS) e área de olho de lombo (AOL) com o auxílio do Ultrassom, com transdutor específico para avaliação de carcaça $(3,5 \mathrm{MHz})$ por um avaliador treinado. As imagens foram tomadas entre o $12^{\circ} \mathrm{e} \mathrm{o}$ $13^{\circ}$ espaço intercostal, exatamente sobre o músculo Longissimus lumborum. Foram realizadas duas avaliações durante o experimento, o primeiro procedimento no primeiro dia ao início do experimento e o segundo procedimento realizado no último dia do experimento.

Quando o experimento completou 130 dias, os animais que apresentavam peso superior a $480 \mathrm{Kg}$, de ambos os grupos, foram encaminhados ao abate, sendo 17 de cada grupo, totalizando 34 animais. A partir desses, foram avaliados o peso de carcaça quente, conformação e acabamento.

No dia do abate os animais passaram por jejum de sólidos de 16 horas, e foram transportados por quatro horas até o frigorífico comercial localizado mesmo município do experimento, seguindo os procedimentos das normas brasileiras.

Após o abate, realizou a análise de tipificação visual subjetiva em categorias de acabamento e conformação atribuindo escores de acordo com o método de tipificação usualmente praticado no Brasil, a análise de acabamento de gordura subcutânea foi avaliada na região da altura da $6^{\text {a }}$ costela, sobre o músculo grande dorsal, em sua parte dorsal; na altura da $9^{\mathrm{a}}$ costela, sobre o músculo grande dorsal, em sua parte ventral e na altura da $12^{\mathrm{a}}$ costela, sobre o músculo serrátil dorsal caudal da carcaça, através de análise visual. As carcaças foram classificadas de 1 a 5 , sendo 1 = gordura ausente, $2=$ gordura escassa, 3 = gordura mediana, 4 = gordura uniforme e 5 = gordura excessiva (MULLER, 1987).

\section{RESULTADOS}

Os bovinos suplementados com ambos os níveis de suplementação (1,2 e 1,8\% de PV) apresentaram altos ganhos de peso 1,13 e $1,25 \mathrm{~kg} / \mathrm{dia}$, respectivamente.

Tabela 04. Médias obtidas do desempenho dos animais durante o período experimental, em função do tratamento.

Table 4. Means obtained from the performance of the animals during the experimental period, as a function of treatment..

\begin{tabular}{|c|c|c|c|c|}
\hline \multirow{2}{*}{ Item } & \multicolumn{2}{|c|}{ Níveis do suplemento $^{1}$} & \multirow{2}{*}{ Média } & \multirow{2}{*}{$\mathrm{CV}(\%)$} \\
\hline & $1,2 \% \mathrm{PC}$ & $1,8 \% \mathrm{PC}$ & & \\
\hline \multicolumn{5}{|c|}{ Peso vivo $(\mathrm{Kg})$} \\
\hline PC Inicial & 370,79 & 365,79 & 368,29 & 10,98 \\
\hline PC (28 dias) & 417,67 & 405,91 & 411,79 & 10,51 \\
\hline PC (56 dias) & 443,58 & 445,50 & 444,54 & 9,73 \\
\hline PC (84 dias) & 481,44 & 495,44 & 488,44 & 8,79 \\
\hline PC (112 dias) & 511,41 & 524,17 & 517,79 & 8,21 \\
\hline PC Final & 515,94 & 527,00 & 521,47 & 8,03 \\
\hline \multicolumn{5}{|c|}{ Ganho de peso $(\mathrm{Kg})$} \\
\hline GP/Total & $145,14 \mathrm{~b}$ & $161,20 \mathrm{a}$ & 153,17 & 18,82 \\
\hline \multicolumn{5}{|c|}{ Área de olho de lombo $\left(\mathrm{cm}^{2}\right)$} \\
\hline AOL Inicial & 33,91 & 34,35 & 34,13 & 11,97 \\
\hline AOL Final & $51,37 \mathrm{~b}$ & $54,23 \mathrm{a}$ & 52,80 & 7,63 \\
\hline \multicolumn{5}{|c|}{ Espessura de gordura subcutâneo $(\mathrm{mm})$} \\
\hline EGS Inicial & 3,02 & 2,95 & 2,98 & 16,16 \\
\hline EGS Final & $4,83 b$ & $5,35 \mathrm{a}$ & 5,09 & 9.29 \\
\hline
\end{tabular}

${ }^{1}$ Médias seguidas de letras diferentes, nas linhas, diferem entre si, pelo teste de Tukey $(\mathrm{P}<0,05)$. PC: peso corporal; GP/TOTAL: ganho de peso no período do experimento; AOL Inicial: área de olho de lombo inicial; AOL Final: área de olho de lombo final; EGS Inicial: espessura de gordura subcutâneo inicial; EGS Final: espessura de gordura subcutâneo final; CV: coeficiente de variação. 
Tendo em vista que o peso de abate foi predeterminado, os níveis de suplementação não diferiram $(\mathrm{P}>0,05)$ nos pesos corporais dos animais nas pesagens feitas durante o experimento e final. Porém, os animais suplementados com $1,8 \%$ do PV obtiveram maior ganho de peso total, maior área de olho de lombo (AOL) final e maior espessura de gordura subcutâneo final $(\mathrm{P}<0,05)$ (Tabela 4).

Os níveis de suplemento não influenciaram significativamente $(\mathrm{P}>0,05)$ no peso de carcaça quente, conformação da carcaça e rendimento da carcaça (Tabela 5). No entanto, os animais que receberam o maior nível de suplementação tiveram melhor acabamento da carcaça $(\mathrm{P}<0,05)$ (tabela 5).

Tabela 5. Médias das características avaliadas pós abate, em função do tratamento.

Table 5. Means of characteristics evaluated after slaughter, as a function of treatment.

\begin{tabular}{|c|c|c|c|c|}
\hline \multirow{2}{*}{ Item } & \multicolumn{2}{|c|}{ Níveis do suplemento 1} & \multirow{2}{*}{ Média } & \multirow{2}{*}{$\mathrm{CV}(\%)$} \\
\hline & $1,2 \% \mathrm{PC}$ & $1,8 \% \mathrm{PC}$ & & \\
\hline $\begin{array}{c}\text { Peso de carcaça } \\
\text { quente }\end{array}$ & 302,34 & 309,72 & 306,03 & 6,21 \\
\hline $\begin{array}{c}\text { Conformação da } \\
\text { carcaça }\end{array}$ & 3,47 & 3,64 & 3,55 & 14,15 \\
\hline $\begin{array}{l}\text { Acabamento da } \\
\text { carcaça }\end{array}$ & $2,41 b$ & $3,52 \mathrm{a}$ & 2,97 & 17,19 \\
\hline $\begin{array}{l}\text { Rendimento da } \\
\text { carcaça }\end{array}$ & 55,30 & 55,03 & 55,17 & 6,19 \\
\hline
\end{tabular}

${ }^{1}$ Médias seguidas de letras diferentes, nas linhas, diferem entre si, pelo teste de Tukey $(\mathrm{P}<0,05)$; CV: coeficiente de variação.

O maior nível de suplementação gerou maior custo inicial, médio e final $(\mathrm{P}<0,05)$. Bem como, provocou maior custo por ganho de peso dos animais $(\mathrm{P}<0,05)$ (Tabela 6).

Tabela 6. Estimativa de custo das dietas experimentais, em função do tratamento.

Table 6. Estimated cost of experimental diets, as a function of treatment.

\begin{tabular}{cccc}
\hline \multirow{2}{*}{ Item } & \multicolumn{2}{c}{ Níveis do suplemento $^{1}$} & \multirow{2}{*}{ Média } \\
\cline { 2 - 3 } & $1,2 \%$ do PC & $1,8 \%$ do PC & \\
\hline Custo Inicial (R\$) & $292,73 \mathrm{~b}$ & $433,18 \mathrm{a}$ & 362,95 \\
Custo Final (R\$) & $407,32 \mathrm{~b}$ & $624,08 \mathrm{a}$ & 515,70 \\
Custo Médio (R\$) & $350,03 \mathrm{~b}$ & $528,63 \mathrm{a}$ & 439,33 \\
Custo/Ganho de & $2,55 \mathrm{~b}$ & $3,33 \mathrm{a}$ & 2,94 \\
peso $\mathrm{R} / \mathrm{Kg}$ & &
\end{tabular}

${ }^{1}$ Médias seguidas de letras diferentes, nas linhas, diferem entre si, pelo teste de Tukey $(\mathrm{P}<0,05)$.

\section{DISCUSSÃO}

Os altos ganhos que os animais apresentaram mostraram que esses foram eficientes em transformar o suplemento em quilograma de PV. Deste modo, a contribuição do efeito associativo positivo pode ter ocorrido entre o suplemento e o pasto, uma vez que a forragem apresentava teor de PB acima de $7 \%$, valor considerado essencial para atividade dos microrganismos do rúmen. Assim, contribuindo para interação entre os componentes da dieta e que, consequentemente, influenciou positivamente a digestibilidade.

O maior ganho de peso total apresentado pelos animais recebendo maior nível de suplementação pode ter sido atribuído ao maior aporte de energia, proteína total e proteína de baixa degradabilidade que a maior porcentagem de concentrado proporcionou.
Além disso, a suplementação reduz as deficiências dos nutrientes, aumentando o crescimento da microbiota ruminal, o que pode influenciar positivamente na fermentação microbiana com maior retirada de carboidratos de forragem, sugerindo aumento na produção de ácidos graxos voláteis, bem como pode aumentar a eficiência de utilização da energia metabolizável provinda da forragem. $\mathrm{O}$ aumento dos microrganismos alavancado pela proteína bruta da dieta faz com que haja maior disponibilidade de proteína microbiana que passa para o intestino e está prontamente para ser absorvida e aproveitada pelo animal (SALES et al., 2011), deste modo, os animais com maior desempenho apresentam maior eficiência ruminal.

Esses resultados estão de acordo com os encontrados por Baroni et al. (2010), que trabalharam com terminação a pasto de novilhos e relataram que o aumento dos níveis de suplementação resulta em aumento linear ao ganho de peso dos animais. Bem como Silva et al. (2010), que trabalharam com suplementação na terminação de novilhos Nelore a pasto e observaram resposta linear crescente dos ganhos de peso conforme o aumento dos níveis de concentrado.

As maiores áreas de olho de lombo obtidas a partir dos animais alimentados com maior nível de suplementação pode ter sido influenciada pelo maior ganho de peso total dos animais durante o período de terminação e pela maior ingestão de nutrientes, permitindo maior disponibilidade de substratos para o maior desenvolvimento muscular.

A área de olho de lombo estimada a partir da tecnologia não invasiva e não destrutiva da ultrassonografia, pode sugerir a composição de carcaça e o rendimento de cortes cárneos de alto valor comercial (DIBIASI et al., 2010). Sendo que a região utilizada para esse procedimento é na área de Longissimus dorsi que é utilizada como indicativo de quantidade de musculosidade da carcaça (VAZ et al., 2010) estando, diretamente correlacionada ao peso do animal.

Neste contexto, Guerra et al. (2016) ao trabalharem com suplementação de bovinos a pasto durante o período das chuvas, observaram maior área de olho de lombo para os bovinos que receberam o maior nível de suplementação, corroborando com os resultados desse trabalho. Porém, esses autores consideraram que esse fato estava correlacionado ao maior peso dos animais e ao maior aporte de nutrientes provindos da suplementação, já os animais deste experimento não diferiram no peso final.

A maior espessura de gordura subcutâneo final dos animais alimentados com maior nível de suplemento pode ser atribuído ao fato dos animais receberam maior quantidade de energia provinda da suplementação. A densidade energética da dieta se correlaciona positivamente com a deposição de gordura na carcaça e ganho de peso dos animais. Quando as exigências de mantença, crescimento dos órgãos e dos tecidos são atendidas, o restante de energia que animal ingere é mantida em reservas sob forma de gordura (MENEZES et al., 2014).

A gordura subcutânea na carcaça é fundamental para preservar a carcaça da desidratação causada pelo rápido resfriamento, diminuindo a perda de peso com o frio. A mensuração dessa gordura é dada pela espessura e os frigoríficos exigem de três a seis mm (SANTOS et al., 2015). Desta forma, os animais deste experimento depositaram uma quantidade de gordura dentro do exigido pela indústria frigorifica.

Neste contexto, é importante os bovinos apresentarem uma deposição de gordura no mínimo de três $\mathrm{mm}$, carcaças com 
acabamentos de gordura menores que essas quantias podem ter a parte da musculatura externa escurecida e maior perda por resfriamento, em detrimento a maior perda de água. Além disso, apresentar encurtamento das fibras musculares, fatores causados pela baixa temperatura da câmera fria e vindo a prejudicar maciez da carne e o seu valor comercial (FERREIRA et al., 2011).

A similaridade do peso final de ambos os tratamentos refletiu em mesmo peso de carcaça quente, conformação da carcaça e rendimento da carcaça dos bovinos. Rezende et al. (2012), ao trabalharem com diferentes níveis de suplementação ( 0,5 e $1 \%$ do PV) não encontraram efeito dos níveis nutricionais sobre o peso de carcaça quente e condicionaram esse fato há similaridade ao mesmo peso dos animais ao abate, indicando a alta correlação entre essas variáveis.

A conformação da carcaça é usada como uma medida subjetiva para mensurar a deposição de tecido muscular que, consequentemente, indica o rendimento de parte comestível (PEREIRA et al., 2015). Desta forma, entende-se que ambos os tratamentos tendem a apresentar o mesmo rendimento da parte comestível. Carcaças com melhor conformação são preteridas pelos frigoríficos e açougues por estarem relacionadas à maior hipertrofia muscular e maior rendimento de carne na desossa (SANTOS et al. 2008), pois exibem menor proporção de osso e maior porção comestível (CRUZ et al., 2015).

A similaridade do rendimento de carcaça entre os animais dos tratamentos pode ter ocorrido, pois as dietas continham altas quantidades de concentrado sendo ofertadas e que influenciaram positivamente na digestibilidade da matéria seca do volumoso e, consequentemente, apresentaram altas taxas de passagem do alimento. Além disso, esses animais eram da mesma idade, grupo genético e peso de abate, sendo fatores preponderantes para o rendimento de carcaça.

Contudo, diferente dos resultados deste trabalho Menezes et al. (2014) relataram que ao trabalharem como níveis de suplementação $(0 ; 0,5$ e $1 \%$ do PV) obtiveram maior rendimento de carcaça para os animais suplementados com o maior nível. Corroborando com os resultados relatados por Marcondes et al. (2011) que tiveram rendimentos de carcaças superiores para animais suplementados com $2 \%$ do PV em relação aqueles suplementados com $1 \%$ do PV.

O teor de gordura na carne e o grau de marmoreio estão intimamente correlacionados ao acabamento da carcaça, essa característica é influenciada pela parte fisiológica do animal, sendo essas afetadas pela raça, sexo e alimentação dos animais. Contudo, esses animais eram do mesmo sexo e da mesma raça, os animais Nelore quando condicionado a pastejo sem suplementação propendem a mínimo acabamento de gordura na carcaça e que pode prejudicar na qualidade da carne (SANTOS et al., 2015). Desta forma, condiciona-se o maior acabamento de gordura na carcaça a maior suplementação que esses animais receberam.

A suplementação com maior porcentagem do peso corporal reduziu o lucro. O maior aporte nutricional aumentou o custo do suplemento, em detrimento a natureza onerosa da maior quantidade de nutrientes da dieta. Como os diferentes ganhos de peso corporal não refletiram a magnitude do aumento de custos houve redução de 0,78 reais por $\mathrm{Kg}$ de ganho de peso, interferindo na rentabilidade.

A estimativa de custo por ganho de peso aumentou com o maior nível de suplementação, porém os resultados poderiam ser mais competitivos, caso houvesse um aumento da carga animal por área, o aumento da taxa de lotação poderia elevar o ganho por área e a lucratividade da propriedade.

Neste sentindo, Silva et al. (2009) em revisão sobre suplementação de bovinos a pasto, relataram que níveis acima de $0,2-0,3 \%$ do peso vivo em oferta de suplemento, já seriam suficientes para que ocorresse efeito substitutivo da pastagem pelo suplemento. Corroborando com Simioni et al. (2009), que relataram houve menor ingestão da forragem pelos animais que recebiam de 0,3 e $0,6 \%$ do PV em relação ao grupo que recebia apenas sal mineral, sugerindo efeito de substituição da forragem pelo suplemento. Essa substituição pode ser utilizada como ferramenta para o aumento da taxa de lotação.

\section{CONCLUSÕES}

Animais suplementados com 1,8\% do PV apresentam maior ganho de peso total, área de olho de lombo, espessura de gordura subcutâneo e acabamento de carcaça. No entanto, os animais apresentam semelhança no ganho de peso final, peso de carcaça quente, rendimento de carcaça e conformação da carcaça com um investimento em ração significativamente menor. Desta forma, com maior custo-benefício a suplementação com $1,2 \%$ do PV resulta em menor custo por quilo de carne produzida, sendo o mais indicado para bovinos terminados em semi-confinamento no período das águas em pastagem de capim Panicum maximum cv. Mombaça.

\section{REFERÊNCIAS}

ASSOCIATION OF OFFICIAL NALYTICAL CHEMISTRY. Official methods of analysis of AOAC International: current thought revision 2. 18. ed. Gaithesburg: MD, 2007.

BARONI, C. E. S.; LANA, R. P.; MANCIO, A. B.; MENDONÇA, B. P. C.; LEÃO, M. I.; SVERZUT, C. B. Consumo e digestibilidade de nutrientes em novilhos suplementados e terminados em pasto, na seca. Arquivo Brasileiro de Medicina Veterinária e Zootecnia, Belo Horizonte, v. 62, n. 2, p. 365-372, 2010. DOI: http://dx.doi.org/10.1590/S0102-09352010000200017

COSTA, V. A. C.; DETMANN, E.; PAUlinO, M. F.; VALADARES FILHO, S. C.; CARVALHO, I. P. C.; MONTEIRO, L. P. Consumo e digestibilidade em bovinos em pastejo durante o período das águas sob suplementação com fontes de compostos nitrogenados e de carboidratos. Revista Brasileira de Zootecnia, Viçosa, v. 40, n. 8, p. 1788-1798, 2011. DOI: http://dx.doi.org/10.1590/S151635982011000800024

CRUZ, R. S.; ALEXANDRINO, E.; MISSIO, R. L.; RESTLE, J.; MELO, J. C.; PAULA NETO, J. J.; SILVA, A. A. M.; SILVA, D. P. Níveis de concentrado e farelo do mesocarpo de babaçu sobre as características da carcaça de tourinhos confinados. Bioscience Journal, Uberlândia, v. 31, n. 1, p. 73-86, 2015. DOI: http://dx.doi.org/10.14393/BJv31n1a2015-18173

DETMANN, E.; VALENTE. E. E. L.; BATISTA, E. D.; HUHTANEN, P. An evaluation of the performance and efficiency of nitrogen utilization in cattle fed tropical grass pastures with supplementation. Livestock Science, Suwon, v. 162, p. 141-153, 2014. DOI: https://dx.doi.org/10.1016/j.livsci.2014.01.029

DIBIASI, N. F.; THOLON, P.; BARROZO, D.; FRIES, L. A.; QUEIROZ, S. A. Estimativas de correlações genéticas entre características de carcaça medidas por 
ultrassonografia e por escores visuais em touros Brangus. ARS VETERINARIA, Jaboticabal, v. 26, n. 1, p. 32-37, 2010.

FERREIRA, E. T.; NABINGER, C.; ELEJALDE, D. A. G.; FREITAS, A. K.; SCHMITT, F.; TAROUCO, J. U. Terminação de novilhos de corte Angus e mestiços em pastagem natural na região da Campanha do RS. Revista Brasileira de Zootecnia, Viçosa, v. 40, n. 9, p. 2048-2057, 2011. DOI: http://dx.doi.org/10.1590/S151635982011000900029

GUERRA, G. L.; MIZUBUTI, I. Y.; RIBEIRO, E. L. A.; CALIXTO, O. P. P.; SILVA, L. D. F.; PEREIRA, E. S.; MASSARO JUNIOR, F. L.; GUERRA, A. L.; FERNANDES JÚNIOR, F.; HENZ, E. L. Supplementation of beef cattle grazing Brachiaria brizantha during the dry and rainy seasons: performance and carcass ultrasound prediction. Semina: Ciências Agrárias, Londrina, v. 37, n. 5, p. 3277-3292, 2016. DOI: http://dx.doi.org/10.5433/1679-0359.2016v37n5p3277

JOHNSON, A. D. Sample preparation and chemical analisys of vegetation. In: MANEJTE, L. T. (Ed.). Measurement of grassland vegetation and animal production. Aberustwysth: Commonweath Agricultural Bureax, 1978. p. 96-102.

LAZZARINI, I.; DETMANN, E.; SAMPAIO, C. B.; PAULINO, M. F.; VALADARES FILHO, S. C.; SOUZA, M. A.; OLIVEIRA, F. A. Intake and digestibility in cattle fed low-quality tropical forage and supplemented with nitrogenous compounds. Revista Brasileira de Zootecnia, Viçosa, v. 38, n. 10, p. 2021-2030, 2009. DOI: http://dx.doi.org/10.1590/S1516-35982009001000024

MARCONDES, M. I.; VALADARES FILHO, S. C.; OLIVEIRA, I. M.; PAULINO, P. V. R.; VALADARES, R. F. D.; DETMANN, E. Eficiência alimentar de bovinos puros e mestiços recebendo alto ou baixo nível de concentrado. Revista Brasileira de Zootecnia, Viçosa, v. 40, n. 6, p. 1313-1324, 2011. DOI: http://dx.doi.org/10.1590/S1516-35982011000600021

MENEZES, L. F. G.; SEGABINAZZI, L. R.; FREITAS, L. S.; RESTLE, J.; BRONDANI, I. L.; CALLEGARO, A. M.; JONER, G.; FILHO, D. C. A. Aspectos qualitativos da carcaça e carne de novilhos superjovens da raça Devon, terminados em pastagem tropical, recebendo diferentes níveis de concentrado. Semina: Ciências Agrárias, Londrina, v. 35, n. 3, p. 1557-1568, 2014. DOI: http://dx.doi.org/10.5433/1679-0359.2014v35n3p1557

MÜLLER, L. Normas para a avaliação de carcaças e concurso de carcaças de novilhos. 2. ed. Santa Maria: Imprensa Universitária, 1987. $31 \mathrm{p}$

PEREIRA, M. M.; REZENDE, C. P.; PEDREIRA, M. S.; PEREIRA, J. M.; MACEDO, T. M.; SILVA, H. G. O.; BORGES, A. M. F.; SILVA, A. M. P. Valor alimentício do capim marandu, adubado ou consorciado com amendoim forrageiro, e características da carcaça de bovinos de corte submetido à pastejo rotacionado. Reista. Brasileira de Saúde e Produção Animal, Salvador, v. 16, n. 3, p. 643-657, 2015 . DOI: http://dx.doi.org/10.1590/S1519-99402015000300015

REIS, R. A.; RUGGIERI, A. C.; CASAGRANDE, D. R.; PÁSCOA, A. G. Suplementação da dieta de bovinos de corte como estratégia do manejo das pastagens. Revista Brasileira de Zootecnia, Viçosa, v. 38, p. 147-159, 2009.
DOI:

35982009001300016

http://dx.doi.org/10.1590/S1516-

REZENDE, P. L. P.; RESTLE, J.; FERNANDES, J. J. R.; FREITAS NETO, M. D.; PRADO, C. S.; PEREIRA, M. L. R. Carcass and meat characteristics of crossbred steers submitted to different nutritional strategies at growing and finishing phases. Ciência Rural, Santa Maria, v. 42, n. 5, p. 875-881, 2012. DOI: http://dx.doi.org/10.1590/S010384782012000500019

SALES, M. F. L.; PAULINO, M. F.; VALADARES FILHO, S. C.; FIGUEIREDO, D. M.; PORTO, M. O.; DETMANN, E. Supplementation levels for growing beef cattle grazing in the dry-rainy transition season. Revista Brasileira de Zootecnia, Viçosa, v. 40, n. 4, p. 904-911, 2011. DOI: http://dx.doi.org/10.1590/S151635982011000400027

SANTOS A. P.; BRONDANI, I. L.; JOÃO RESTLE, J.; MENEZES, L. F. G.; OLIVEIRA, L.; SILVEIRA, S. R. L. Características quantitativas da carcaça de novilhos jovens e superjovens com peso de abate similares. Ciência Animal Brasileira, Goiânia, v. 9, n. 2, p. 300-308, 2008.

SANTOS, M. S. dos; NOGUEIRA, H. C.; FERREIRA, R. R.; SANTOS, P. B. dos; LEÃO, E. de S.; OLIVEIRA, A. P. de; SANTANA JÚNIOR, H. A. de. Qualidade da carne de bovinos terminados em pastejo. Arquivos de Ciência Veterinária e Zoologia. UNIPAR, Umuarama, v. 18, n. 2, p. 109-114, 2015. DOI: http://dx.doi.org/10.25110/arqvet.v18i2.2015.5381

SIMIONI, F. L.; ANDRADE, I. F.; LADEIRA, M. M.; GONÇALVES, T. M.; MATA JÚNIOR, J. I.; CAMPOS, F. R. Níveis e frequência de suplementação de novilhos de corte a pasto na estação seca. Revista Brasileira de Zootecnia, Viçosa, v. 38, n. 10, p. 2045-2052, 2009. DOI: http://dx.doi.org/10.1590/S1516-35982009001000027

SILVA, F. F.; SÁ, J. F.; SCHIO, A. R.; ÍTAVO, L. C. V.; SILVA, R. R.; MATEUS, R. G. Suplementação a pasto: disponibilidade e qualidade $\mathrm{x}$ níveis de suplementação $\mathrm{x}$ desempenho. Revista Brasileira de Zootecnia, Viçosa, v. 38, p. 371-389, 2009. DOI: http://dx.doi.org/10.1590/S1516-35982009001300037

SILVA, R. R.; PRADO, I. N.; CARVALHO, G. G. P.; SILVA, F. F.; ALMEIDA, V. V. S.; SANTANA JÚNIOR, H. A.; PAIXÃO, M. L.; ABREU FILHO, G. Níveis de suplementação na terminação de novilhos Nelore em pastagens: aspectos econômicos. Revista Brasileira de Zootecnia, Viçosa, v. 39, n. 9, p. 2091-2097, 2010. DOI: http://dx.doi.org/10.1590/S1516-35982010000900030

SOUZA, M. A.; DETMANN, E.; PAULINO, M. F.; SAMPAIO, C. B.; LAZZARINI, I.; VALADARES FILHO, S. C. Intake, digestibility and rumen dynamics of neutral detergent fibre in cattle fed low-quality tropical forage and supplemented with nitrogen and/or starch. Tropical Animal Health Prodction, v. 42, n. 6, p. 1299 1310, 2010. http://dx.doi.org/10.1007/s1 1250-010-9566-6 VALADARES FILHO, S. C.; PAULINO, P. V. R.; MAGALHÃES, K. A. Exigências nutricionais de zebuínos e tabelas de composição de alimentos. 1. ed. Viçosa: Unversidade Federal de Viçosa. p.142, 2006.

VAN SOEST, P. J.; ROBERTSON, J. B.; LEWIS, B. A. Methods for dietary fiber, anda nonstarch polyssacarides in relations to animal nutrition. Journal Dairy Science, v. 74 , n. $10, \quad$ p. $3583-3597$, 1991. DOI: https://dx.doi.org/10.3168/jds.S0022-0302(91)78551-2 
VAZ, F. N.; RESTLE, J.; ARBOITE, M. Z.; PASCOAL, L. L.; ALVES FILHO, D. C.; PACHECO, R. F. Características de carcaça e da carne de novilhos e novilhas superjovens, terminados com suplementação em pastagem cultivada. Ciência Animal Brasileira, Goiânia, v. 11, n. 1, p. $\quad 42-52, \quad 2010 . \quad$ DOI: http://dx.doi.org/10.5216/cab.v11i1.5131 